\title{
LA DISPUTA MARÍTIMA ENTRE PERÚ Y CHILE: COMENTARIO DE LA SENTENCIA DE LA CORTE INTERNACIONAL DE JUSTICIA, DE FECHA 27 DE ENERO DE $2014^{*}$
}

\author{
THE MARITIME DISPUTE BETWEEN PERU AND CHILE: COMMENT \\ OF THE JUDGMENT OF THE INTERNATIONAL COURT OF JUSTICE, \\ DATED JANUARY $27^{T H}, 2014$
}

\section{Sebastián López EsCARCEnA ${ }^{* *}$}

\begin{abstract}
RESUMEN: El 16 de enero del 2008, Perú solicitó a la Corte Internacional de Justicia que delimite su frontera marítima con Chile. Seis años más tarde, el tribunal aceptó parcialmente los argumentos de ambas partes en su fallo. Algo parecido ocurrió el 2012 con otro caso resuelto por la Corte, esta vez entre Nicaragua y Colombia. La correcta comprensión de la sentencia recaída en la disputa marítima (Perú c. Chile) requiere de una atenta lectura de lo resuelto por la Corte en la disputa territorial y marítima (Nicaragua c. Colombia). Son varias las similitudes de hecho y de derecho entre estos casos, cuyas sentencias provocaron desazón en círculos estatales y académicos latinoamericanos. Las soluciones jurisprudenciales dadas a los diferendos del Mar Caribe y del Océano Pacífico confirman una creciente visión crítica del actuar de la Corte, que eventualmente puede resultar dañina para la solución pacífica de las controversias internacionales en esta región.
\end{abstract}

Palabras clave: Corte Internacional de Justicia; Pacto de Bogotá; delimitación marítima; método de solución equitativa.

ABSTRACT: On 16 January 2008, Peru asked the International Court of Justice to delimit its maritime boundary with Chile. Six years later, the tribunal partially accepted the arguments of both parties in its judgment. Something similar happened in 2012 with another case settled by the Court, this time between Nicaragua and Colombia. The correct comprehension of the judgment in the Maritime Dispute (Peru v. Chile) requires a careful reading of the Court's decisions in the Maritime and Territorial Dispute (Nicaragua v. Colombia). There are several factual and legal similarities between these cases, whose judgments produced unease in Latin American state and academic circles. The jurisprudential solution given to the disputes of the Caribbean Sea and the Pacific Ocean confirm a growing critical vision towards the work of the Court, which might prove harmful for the settlement of international disputes in this region.

Key words: International Court of Justice; Bogotá Pact; maritime delimitation; equitative solution method.

\footnotetext{
* Trabajo presentado en Bogotá el 15 de agosto de 2014, en la III Conferencia Bienal de la Sociedad Latinoamericana de Derecho Internacional organizada por Facultad de Derecho de la Universidad Externado de Colombia. El autor agradece las observaciones de los profesores Gattas Abugattas de la Pontificia Universidad Católica del Perú, y Osvaldo Urrutia de la Pontificia Universidad Católica de Valparaíso. Cualquier error en este texto, es responsabilidad exclusiva de su autor.

** Profesor asociado de la Facultad de Derecho de la Pontificia Universidad Católica de Chile, e investigador asociado (associate fellow/ membre associè) del Centro para el Estudio de la Gobernanza Global de la Universidad
} 


\section{INTRODUCCIÓN}

La disputa maritima (Perú c. Chile) fue resuelta el 27 de enero del 2014 por la Corte Internacional de Justicia (CIJ). El proceso duró seis años. Comenzó con la presentación de la solicitud por Perú el 2008, y continuó con la entrega de la memoria del Estado demandante el 2009, la contramemoria de Chile el 2010, la réplica peruana del mismo año, y la dúplica chilena del 2011, y con los alegatos que se llevaron a cabo a fines del $2012^{1}$. En todo momento de su tramitación, las partes en litigio estuvieron pendientes de lo que sucedía en otra controversia llevada ante el mismo tribunal internacional, unos años antes. La disputa territorial y maritima (Nicaragua c. Colombia), fallada el 19 de noviembre del 2012, reunió muchas de las características que después se presentaron en el diferendo entre Perú y Chile ${ }^{2}$. En ambos casos, un estado le solicitó a la CIJ que delimite la frontera con un vecino, desconociendo los límites establecidos en tratados bilaterales vigentes entre las partes contendientes, y reclamando un territorio ocupado por dicho Estado. Tanto en la controversia del Mar Caribe como en el diferendo del Océano del Pacífico, los demandantes pidieron una solución equitativa a la CIJ en virtud del artículo XXXI del Tratado Americano de Soluciones Pacíficas de 1948, más conocido como Pacto de Bogotá ${ }^{3}$. Con nada que perder, y todo por ganar, Nicaragua y Perú iniciaron un proceso destinado a modificar el trazado de la frontera marítima que, al menos en los hechos, los separaba hasta ese momento de Colombia y Chile. En el peor de los escenarios, la sentencia de la CIJ solo confirmaría una realidad ya existente. Algo que a la larga, no sucedió.

El presente comentario analiza la disputa marítima entre Perú y Chile, explicando sus antecedentes de hecho y de derecho, y exponiendo los argumentos esgrimidos por las partes y lo fallado por la CIJ. En concreto, lo que la sentencia resolvió no solo respecto de la existencia de un límite marítimo entre ambos Estados según las declaraciones unilaterales de Chile y Perú de 1947, la Declaración de Santiago de 1952, el Convenio sobre Zona Especial Fronteriza Marítima de 1954, y las marcas de enfilación de 1968 y 1969, sino

Católica de Lovaina, Bélgica, y del Instituto de Investigación en Derecho Internacional y Europeo de la Universidad de París 1 "Panthéon-Sorbonne", Francia. PhD (Edimburgo), LLM (Leiden), Abogado y Licenciado en Derecho (Católica de Chile). Correo electrónico: rlopeze@uc.cl

1 Los escritos y alegatos de las partes litigantes en este caso, así como las respectivas decisiones judiciales de la CIJ, están disponibles en: <http://www.icj-cij.org/docket/index.php?p1=3\&p2=3\&code=pch\&case=137\&k=88 \&p3=0> [fecha de consulta: 30 de septiembre de 2014].

Hay una traducción de esta sentencia al castellano. Disponible en: <http://www.anuariocdi.org/anuario2014/ ACDI_7_RAbello\%20et\%20al.pdf> [fecha de consulta: 30 de septiembre de 2014].

Se han publicado resúmenes de los escritos de las partes, y de la sentencia de la CIJ. Ver en general WINTER (2013); Lagos Erazo (2014a); Lagos Erazo (2014b); y Llanos y Cabrera (2014).

2 Los escritos y alegatos de las partes en litigio, y las respectivas decisiones judiciales de la CIJ en este caso, están disponibles en: <http://www.icj-cij.org/docket/index.php?p1=3\&p2=3\&code=nicol\&case=124\&k=e2 \&p3=0> [fecha de consulta: 30 de septiembre de 2014].

Existe una traducción al castellano de esta sentencia. Disponible en: <http://www.anuariocdi.org/anuario2012/ ACDI\%20Vol\%205\%20El\%20diferendo\%20territorial\%20y\%20maritimo.pdf> [fecha de consulta: 30 de septiembre de 2014].

3 El Tratado Americano de Soluciones Pacíficas de 1948 está en vigor desde 1949. Disponible en: <http://www. oas.org/juridico/spanish/tratados/a-42.html> [fecha de consulta: 30 de septiembre de 2014]. 
también sobre la naturaleza, extensión y punto de inicio de dicho límite. Este comentario reseña, asimismo, las similitudes de la controversia internacional entre Perú y Chile con el diferendo entre Nicaragua y Colombia, y las preguntas que quedaron sin respuesta a partir de la dictación de ambas sentencias por la CIJ.

\section{CAMINO A LA HAYA}

La actual frontera chileno-peruana fue establecida en los años posteriores al término de la Guerra del Pacífico, o Guerra del Salitre, que enfrentó a Chile con Bolivia y Perú entre los años 1879 y 18834. Por el Tratado de Paz y Amistad de 1883, también llamado Tratado de Ancón, Perú cedió a Chile "perpetua e incondicionalmente" la provincia de Tarapacá . Para las provincias de Tacna y Arica, el Tratado de Ancón dispuso que estas seguirían en poder de Chile por un plazo de diez años a contar de su ratificación, tras el cual se realizaría un plebiscito para decidir si dichas provincias permanecerían bajo soberanía chilena o peruana ${ }^{6}$. Por diversos motivos, este plebiscito no se llevó a cabo en los años siguientes, debiendo ambos Estados negociar un nuevo acuerdo internacional ${ }^{7}$. A través del Tratado de Lima de 1929, la provincia de Tacna volvió a Perú y la de Arica permaneció en poder de Chile ${ }^{8}$. Este tratado estableció una línea divisoria que:

partirá de un punto de la costa que se denominará 'Concordia', distante diez kilómetros al norte del puente del río Lluta, para seguir hacia el oriente paralela a la vía de la sección chilena del ferrocarril de Arica a La Paz, y distante diez kilómetros de ella [... $]^{9}$.

Ese mismo año, Chile y Perú celebraron un protocolo complementario al Tratado de Lima que señaló:

Los Gobiernos de Chile y del Perú, no podrán, sin previo acuerdo entre ellos, ceder a una tercera potencia la totalidad o parte de los territorios que, en conformidad al Tratado de esta misma fecha, quedan bajo sus respectivas soberanías $[\ldots]^{10}$.

En esta disposición se encontraría el origen remoto de la disputa maritima (Perú c. Chile). El reciente conflicto entre peruanos y chilenos solo puede entenderse a cabalidad desde la perspectiva del ya antiguo problema tripartito de la mediterraneidad boliviana pos-

\footnotetext{
4 Respecto a la Guerra del Pacífico ver en general Cluny (2000); Farcau (2000); y Sater (2007).

5 Art. 2 del Tratado de Paz y Amistad entre Chile y Perú de 1883. Disponible en: <http://www.leychile.cl/ Navegar?idNorma=220112> [fecha de consulta: 30 de septiembre de 2014].

6 Art. 3 del Tratado de Paz y Amistad entre Chile y Perú de 1883.

7 En cuanto a la fijación del límite terrestre entre Chile y Perú, ver Benadava (1993), pp. 37-43; Lira (2009) pp. 139-46; y LaGos Erazo (2010) pp. 25-33.

8 Art. 2 del Tratado de Paz y Amistad entre Chile y Perú de 1929. Disponible en: <http://www.leychile.cl/ Navegar?idNorma=220134> [fecha de consulta: 30 de septiembre de 2014].

9 Art. 2 del Tratado de Paz y Amistad entre Chile y Perú de 1929.

10 Art. 1 del Protocolo Complementario al Tratado de Paz y Amistad entre Chile y Perú de 1929. Disponible en: <http://www.leychile.cl/Navegar?idNorma=220135> [fecha de consulta: 30 de septiembre de 2014].
} 
terior a la Guerra del Pacífico ${ }^{11}$. Por casi un siglo y medio, los intereses de Bolivia, Chile y Perú han girado en torno a un mismo punto geográfico: la ciudad de Arica, salida natural al Océano Pacífico para los bolivianos, puerta de entrada al norte grande para los chilenos, y principal ciudad portuaria de una provincia cautiva para no pocos peruanos ${ }^{12}$. Este contexto explica el planteamiento del ex almirante peruano Guillermo Faura, rescatado del olvido por el escritor chileno José Rodríguez Elizondo. Con cargo a su peculio, Faura publicó en 1977 un libro titulado "El mar peruano y sus límites", donde señaló que el empleo del paralelo como límite marítimo era desfavorable a Perú de acuerdo a las normas del entonces nuevo derecho del $\operatorname{mar}^{13}$. Ese mismo año habían fracasado las negociaciones entre Chile y Bolivia, por medio de las cuales el primero proponía canjear un corredor territorial al norte de la línea férrea Arica-La Paz en favor del segundo. Este acuerdo frustrado pasó a la posteridad como abrazo de Charaña, por el ampliamente difundido gesto simbólico de los presidentes Augusto Pinochet y Hugo Banzer que tuvo lugar en esa localidad en $1975^{14}$. Al momento de aparecer el libro de Faura, ya estaban vigentes la Declaración sobre Zona Marítima de 1952 y el Convenio sobre Zona Especial Fronteriza Marítima de 1954, ambos formulados y celebrados por Chile, Ecuador y Perú. La Declaración de Santiago de 1952 dispuso:

los Gobiernos de Chile, Ecuador y Perú proclaman como norma de su política internacional marítima, la soberanía y jurisdicción exclusivas que a cada uno de ellos corresponde sobre el mar que baña las costas de sus respectivos países, hasta una distancia mínima de 200 millas marinas desde las referidas costas ${ }^{15}$.

\footnotetext{
11 Finalizada la Guerra del Pacífico, los Estados boliviano y chileno celebraron un pacto de tregua en 1884 , en virtud del cual se mantuvo bajo el poder de Chile el territorio ocupado durante el conflicto armado. Un año más tarde, ambos estados celebraron tres nuevos tratados: uno de paz y amistad, uno de trasferencia de territorio y uno de comercio. De haber entrado en vigencia, estos tratados habrían puesto fin al problema de la mediterraneidad boliviana. Sin embargo, eso no ocurrió. Solo se logró un acuerdo definitivo para el territorio ocupado durante la Guerra del Pacífico en el Tratado de Paz y Amistad entre Chile y Bolivia de 1904. En este tratado se reconoció el "dominio absoluto y perpetuo" de Chile sobre dicho territorio a cambio de ciertos beneficios favorables a Bolivia, como un derecho perpetuo de libre tránsito comercial por esta zona, la construcción de un ferrocarril entre Arica y La Paz, y el cumplimiento de onerosas obligaciones financieras por Chile.

Ver arts. I-X del Tratado de Paz, Amistad y Comercio entre Bolivia y Chile de 1904. Disponible en: <http:// www.difrol.cl/index.php?option $=$ com_content\&task=view\&id $=26 \& I t e m i d=12 \% 20$ Tratado $\% 20 \mathrm{de} \% 20 \mathrm{Paz} \% 20$ y\%20Amistad> [fecha de consulta: 30 de septiembre de 2014].

Sobre la fijación de la frontera entre Bolivia y Chile, ver Benadava (1993) pp. 25-32; FigueroA (2007) pp. 21 33; y LIRA (2009) pp. 146-69.

12 Ver Pinochet de la Barra (2004); Rodríguez Elizondo (2009); Rodríguez Elizondo (2010a); Rodríguez Elizondo (2010b); Rodríguez Elizondo (2012); y Rodríguez Elizondo (2014). Ver también Cluny (2000).

${ }_{13}$ Las que quedarían recogidas más tarde en la Convención de las Naciones Unidas sobre el Derecho del Mar de 1982 (Convemar), que entró en vigor en 1994 y está disponible en: <http://www.un.org/deggpts/los/ convention_agreements/texts/unclos/convemar_es.pdf> [fecha de consulta: 30 de septiembre de 2014]. Ver en general FAURA (1977).

${ }^{14}$ En cuanto al llamado abrazo de Charaña, ver Pinochet de la Barra (2004) pp. 75-87; Figueroa (2007) pp. 117-37; Lira (2009) pp. 322-69; Rodríguez Elizondo (2009) pp. 21-30; Lagos Erazo (2010) pp. 33-7; y TAPia y Mardones (2011) pp. 37-64.

15 Párrafo 3 II) de la Declaración sobre Zona Marítima de 1952, formulada por Chile, Ecuador y Perú. Disponible en: <http://www.difrol.cl/index.php?option=com_content\&task=view\&id=34\&Itemid=12> [fecha de consulta: 30 de septiembre de 2014].
} 
Para el territorio insular de las partes, ubicado dentro de las mencionadas 200 millas marinas o náuticas, esta declaración señaló:

Si una isla o grupo de islas pertenecientes a uno de los países declarantes estuviere a menos de 200 millas marinas de la zona marítima general que corresponde a otro de ellos, la zona marítima de esta isla o grupo de islas quedará limitada por el paralelo del punto en que llega al mar la frontera terrestre de los Estados respectivos ${ }^{16}$.

El Convenio sobre Zona Especial Fronteriza Marítima de 1954 estableció un área especial "a partir de las 12 millas marinas de la costa, de 10 millas marinas de ancho a cada lado del paralelo que constituye el límite marítimo entre los dos países”, en la cual la presencia accidental de embarcaciones de cualquiera de los Estados limítrofes "no será considerada como violación de las aguas de la zona marítima, sin que esto signifique reconocimientos de derecho alguno para ejercer faenas de pesca o caza con propósito preconcebido en dicha Zona Especial" ${ }^{17}$.

Según Faura, ni la Declaración sobre Zona Marítima de 1952 ni el Convenio sobre Zona Especial Fronteriza Marítima de 1954 tendrían carácter limítrofe, por lo que Chile y Perú deberían negociar un tratado específico de delimitación marítima que establezca una línea media trazada de acuerdo al principio de equidistancia de las costas. En caso de no llegarse a esta negociación, Faura recomendó solucionar la controversia por medio del arbitraje que contempla la Carta de la $\mathrm{ONU}^{18}$. Es claro el vínculo existente entre la propuesta de Faura y la posterior demanda de Perú contra Chile ante la CIJ. Rodríguez Elizondo lo resume de la siguiente manera:

Tres largas décadas después, el equipo peruano en La Haya ejecutaría esta tesis: ausencia de tratado fronterizo marítimo específico, reducción de los tratados de 1952 y 1954 a 'convenios pesqueros', improcedencia del paralelo como definición de frontera en el mar y 'línea media' como elemento de equidad. Solo que, en vez de negociación o arbitraje, Perú produjo una demanda judicial ${ }^{19}$.

Conforme a esta declaración, "[1]a jurisdicción y soberanía exclusivas sobre la zona marítima indicada, incluye también la soberanía y jurisdicción exclusivas sobre el suelo y subsuelo que a ella corresponde”. Párrafo 3 III) de la Declaración sobre Zona Marítima de 1952.

16 Párrafo IV de la Declaración sobre Zona Marítima de 1952.

17 Arts. 1 y 2 del Convenio sobre Zona Especial Fronteriza Marítima de 1954, celebrado por Chile, Ecuador y Perú. Disponible en: <http://www.difrol.cl/index.php?option=com_content\&task=view\&id=35\&Itemid=12> [fecha de consulta: 30 de septiembre de 2014].

18 Ver art. 33 de la Carta de la ONU. En vigor a contar de 1945 y disponible en: <http://www.un.org/es/ documents/charter/> [fecha de consulta: 30 de septiembre de 2014]. Sobre la tesis de Faura, ver RodRíGUEZ Elizondo (2009) pp. 71-81; Rodríguez Elizondo (2010a) pp. 27-8 \& 31-4; Rodríguez Elizondo (2010b) pp. 139-41; Rodríguez Elizondo (2012) pp. 713-4; y Rodríguez Elizondo (2014) pp. 19-25. Ver también Winter (2013) pp. 26-7; Durán (2014) pp. 23-4; y Lagos Erazo (2014b) pp. 46-7.

19 Rodríguez Elizondo (2014) p. 23. Con posterioridad a Faura, son relevantes en la elaboración de la posición peruana los libros de Eduardo Ferrero, Juan Miguel Bákula, Marisol Agüero, y Manuel Rodríguez Cuadros. Ver en general Ferrero (1979); Bákula (1985); Agüero (2001); Bákula (2002); Rodríguez Cuadros (2007); Bákula (2008); y Rodríguez Cuadros (2010). 
En virtud de lo dispuesto en el artículo XXXI del Pacto de Bogotá, el 16 de enero del 2008 Perú presentó a la CIJ la solicitud que dio inicio a un proceso que terminó el 2014, con una sentencia que no dejó realmente conforme a ninguna de las partes litigantes $^{20}$. Durante este proceso, Perú señaló que la frontera marítima con Chile no estaba delimitada, por lo que solicitó a la CIJ que lo haga en virtud del método equitativo del derecho internacional, a partir de un punto denominado "Concordia" ubicado en la costa del Océano Pacífico donde empezaría la frontera terrestre entre ambos estados ${ }^{21}$. Más allá del punto en el cual termina la frontera marítima común con Chile, Perú agregó que tenía derechos exclusivos sobre un área marítima que se extiende hasta una distancia de 200 millas náuticas contadas desde su costa ${ }^{22}$. Según el Estado demandante, la línea de delimitación propuesta por Chile sería inequitativa, por cuanto le otorga al Estado demandado una extensión marítima que es más del doble de la que queda para el Estado demandante ${ }^{23}$. Chile, por su parte, señaló que la frontera marítima estaba delimitada desde la Declaración de Santiago de 1952 a través de una línea que se extiende a un mínimo de 200 millas marinas y que pasa por el paralelo de latitud que comienza en un punto de la frontera terrestre común con Perú, conocido como "Hito No 1" 24 . El Estado demandado solicitó a la CIJ que confirme este límite marítimo convencional, en virtud de los principios pacta sunt servanda y de estabilidad de las fronteras ${ }^{25}$.

\section{LO RESUELTO POR LA CORTE}

La sentencia del 27 de enero del 2014 comenzó por reconocer que el Tratado de Lima de 1929 estableció la frontera terrestre entre Chile y Perú ${ }^{26}$. Respecto a la existencia de un límite marítimo, la CIJ analizó los siguientes antecedentes: las declaraciones unilaterales de Chile y Perú de 1947; la Declaración sobre Zona Marítima de 1952; diversos

\footnotetext{
Respecto a los antecedentes diplomáticos de la demanda de Perú, ver RodríGuez Elizondo (2009), pp. 81-239; Lagos Erazo (2010) pp. 23-4 \& 169-81; Rodríguez Elizondo (2012) pp. 714-23; Winter (2013) pp. 24-37; Durán (2014) pp. 15-115; Lagos Erazo (2014b) pp. 43-55; y Rodríguez Elizondo (2014) pp. 29-73.

20 Ver disputa marítima, Perú c. Chile (2014): CIJ (sentencia) párrafo 1. El art. XXXI del Pacto de Bogotá señala: De conformidad con el inciso $2^{\circ}$ del artículo 36 del Estatuto de la Corte Internacional de Justicia, las Altas Partes Contratantes declaran que reconocen respecto a cualquier otro Estado Americano como obligatoria ipso facto, sin necesidad de ningún convenio especial mientras esté vigente el presente Tratado, la jurisdicción de la expresada Corte en todas las controversias de orden jurídico que surjan entre ellas y que versen sobre:

a) La interpretación de un Tratado;

b) Cualquier cuestión de Derecho Internacional;

c) La existencia de todo hecho que, si fuere establecido, constituiría la violación de una obligación internacional;

d) La naturaleza o extensión de la reparación que ha de hacerse por el quebrantamiento de una obligación internacional.

${ }^{21}$ Ver disputa marítima, Perú c. Chile (2014): CIJ (sentencia) párrafos 13-4 \& 22.

22 Ver disputa maritima, Perú c. Chile (2014): CIJ (sentencia) párrafos 14 \& 22.

23 Ver disputa marítima, Perú c. Chile (2014): CIJ (sentencia) párrafo 23.

24 Ver disputa maritima, Perú c. Chile (2014): CIJ (sentencia) párrafos $14 \& 22$.

25 Ver disputa maritima, Perú c. Chile (2014): CIJ (sentencia) párrafos 22-3.

26 Ver disputa marítima, Perú c. Chile (2014): CIJ (sentencia) párrafo 18. Ver también disputa marítima, Perú c. Chile (2014): CIJ (sentencia) párrafo 153.
} 
acuerdos de 1954; y las marcas de enfilación de 1968 y $1969^{27}$. Por medio de las declaraciones de 1947, los presidentes Gabriel González Videla y José Luis Bustamante y Rivero proclamaron derechos marítimos para Chile y Perú sobre una zona que se extiende hasta 200 millas náuticas desde sus $\operatorname{costas}^{28}$. El tribunal internacional observó que conforme lo señalado por ambas partes en litigio, tales declaraciones no establecieron por sí mismas una frontera marítima ${ }^{29}$. Por esta razón, únicamente les asignó importancia probatoria en relación a un futuro acuerdo de límites marítimos ${ }^{30}$. Si bien la CIJ no tuvo problemas en reconocer la Declaración sobre Zona Marítima de 1952 como un tratado, se preguntó si este acuerdo estableció una frontera marítima ${ }^{31}$. Al respecto, el tribunal observó que la Declaración de Santiago de 1952 no se refirió expresamente a dicha frontera, ni señaló coordenadas o acompañó material cartográfico ${ }^{32}$. Según la CIJ, ni su párrafo II ni III hicieron mención explícita de límites paralelos para las proclamadas zonas de 200 millas marinas ${ }^{33}$. Por su parte, el párrafo IV se refirió exclusivamente al caso de la existencia de una isla o grupo de islas de alguna de las partes ubicadas a menos de 200 millas náuticas de la zona marítima general de cada Estado, en cuya situación se aplica el paralelo geográfico como límite marítimo desde el punto donde comienza la frontera terrestre correspondiente ${ }^{34}$. En su momento, las únicas islas que se tuvieron en cuenta para estos efectos fueron las Galápagos ${ }^{35}$. Sin perjuicio de lo anterior, la utilización del paralelo geográfico para las islas de una de las partes en la Declaración sobre Zona Marítima de 1952 llevó a la CIJ a concluir que puede haber existido una especie de entendimiento común sobre límites marítimos de carácter general, aun cuando dicho acuerdo internacional no lo haya establecido expresamente ${ }^{36}$.

Dentro de los otros instrumentos jurídicos que analizó la sentencia, a fin de determinar la existencia de un límite marítimo entre Chile y Perú, estuvieron el Acuerdo Complementario de 1954 a la Declaración sobre Zona Marítima de 1952, el Acuerdo sobre Medidas de Supervisión y Control de las Zonas Marítimas de 1954, y el Convenio sobre Zona Especial Fronteriza Marítima del mismo año. Para la CIJ, el principal objetivo que tuvo el Acuerdo Complementario de 1954 fue reiterar el reclamo de soberanía y jurisdicción de las partes de la Declaración de Santiago de 1952 contra las principales potencias marítimas ${ }^{37}$. En opinión de la CIJ, si bien para 1954 se podían distinguir tres zonas marítimas bajo la jurisdicción de las partes de la Declaración de Santiago y de su Acuerdo Complementario,

27 Ver disputa marítima, Perú c. Chile (2014): CIJ (sentencia) párrafo 24.

28 Ver disputa marítima, Perú c. Chile (2014): CIJ (sentencia) párrafo 25.

29 Ver disputa marítima, Perú c. Chile (2014): CIJ (sentencia) párrafo 39.

${ }^{30}$ Ver disputa marítima, Perú c. Chile (2014): CIJ (sentencia) párrafo 43. Ver también disputa marítima, Perú c. Chile (2014): CIJ (sentencia) párrafos 39-42.

31 Ver disputa maritima, Perú c. Chile (2014): CIJ (sentencia) párrafo 48.

32 Ver disputa maritima, Perú c. Chile (2014): CIJ (sentencia) párrafo 58.

33 Ver disputa maritima, Perú c. Chile (2014): CIJ (sentencia) párrafo 59.

34 Ver disputa marítima, Perú c. Chile (2014): CIJ (sentencia) párrafos 60-2.

35 Ver disputa maritima, Perú c. Chile (2014): CIJ (sentencia) párrafos 64.

Ver también disputa marítima, Perú c. Chile (2014): CIJ (sentencia) párrafo 68.

36 Ver disputa marítima, Perú c. Chile (2014): CIJ (sentencia) párrafos 69-70.

37 Ver disputa marítima, Perú c. Chile (2014): CIJ (sentencia) párrafo 77. 
ni estos instrumentos ni el Acuerdo sobre Medidas de Supervisión y Control de las Zonas Marítimas de ese mismo año reflejaron la ubicación o naturaleza de los límites marítimos entre Chile y Perú $^{38}$. A juicio del tribunal, la existencia de esta frontera o límite marítimo sí se reconoció en el Convenio sobre Zona Especial Fronteriza Marítima de 1954, pero sin indicación de cuándo y cómo fue acordado. En virtud de lo anterior, la CIJ concluyó que ya existía un acuerdo tácito antes de este tratado, confirmando lo ya adelantado en su sentencia respecto de las declaraciones unilaterales de 1947 y la Declaración de Santiago de $1952^{39}$. Respecto de las marcas de enfilación de 1968 y 1969, el tribunal señaló que su objetivo fue limitado y que se establecieron sobre la base de una frontera marítima que se extiende sobre el paralelo geográfico más allá de las 12 millas náuticas, como lo había indicado antes el Convenio sobre Zona Especial Fronteriza Marítima de $1954^{40}$.

Una vez establecido que el límite marítimo entre las partes en litigio fue acordado tácitamente con anterioridad a 1954, la sentencia procedió a determinar su naturaleza y extensión. En virtud de las declaraciones unilaterales de Chile y Perú de 1947 y la Declaración de Santiago de 1952, el tribunal resolvió que la frontera marítima entre los Estados en litigio es un límite a todo propósito que comprende el suelo, subsuelo y aguas subyacentes $^{41}$. La CIJ consideró que el objetivo del Convenio sobre Zona Especial Fronteriza Marítima de 1954 no era otro que establecer un área de tolerancia para la actividad pesquera de embarcaciones pequeñas de los Estados partes a lo largo del límite marítimo paralelo, la cual se extendía a la distancia de 60 millas marinas en que dicha actividad tenía lugar por esos años ${ }^{42}$. Esta circunstancia, sumada al desarrollo contemporáneo del derecho del mar en la década de los 50, le bastó al tribunal para concluir que el límite marítimo paralelo establecido no puede haber pasado de las 80 millas náuticas ${ }^{43}$. Del examen de la práctica legislativa; del Protocolo de Accesión de 1955 a la Declaración de Santiago; de las actividades de ejecución del límite marítimo; de las actas de 1968 y 1969; de las negociaciones con Bolivia entre 1975 y 1976; de la posición de las partes en la III Conferencia de la ONU sobre Derecho del Mar de 1982; del así denominado "memorándum Bákula” de 1986; y de la práctica posterior a ese año, la CIJ concluyó que el límite marítimo acordado tácitamente

\footnotetext{
38 Ver disputa marítima, Perú c. Chile (2014): CIJ (sentencia) párrafo 79.

39 Ver disputa maritima, Perú c. Chile (2014): CIJ (sentencia) párrafos 90-2. Ver también disputa marítima, Perú c. Chile (2014): CIJ (sentencia) párrafos 73, 85, 87 \& 95. Al respecto, la CIJ citó el caso de Nicaragua con Honduras fallado en el 2007. Ver disputa territorial y maritima, Nicaragua c. Honduras (2007): CIJ (sentencia) párrafo 253. Sobre la disputa territorial entre Nicaragua y Honduras, ver en general TANAKA (2008).

40 Ver disputa maritima, Perú c. Chile (2014): CIJ (sentencia) párrafo 99. Ver también disputa marítima, Perú c. Chile (2014): CIJ (sentencia) párrafo 96.

41 Ver disputa marítima, Perú c. Chile (2014): CIJ (sentencia) párrafos $100 \& 102$.

42 Ver disputa maritima, Perúc. Chile (2014): CIJ (sentencia) párrafos 103 \& 108.

Ver también disputa marítima, Perú c. Chile (2014): CIJ (sentencia) párrafos 109-11.

43 Ver disputa maritima, Perú c. Chile (2014): CIJ (sentencia) párrafos 117 \& 198. Ver también disputa maritima, Perú c. Chile (2014): CIJ (sentencia) párrafos 112-6. En este punto, la CIJ se refirió al caso de Rumania y Ucrania fallado en el 2009. Ver asunto de la delimitación maritima en el Mar Negro, Rumania c. Ucrania (2009): CIJ (sentencia) párrafo 70. En cuanto al asunto de la delimitación marítima en el Mar Negro, ver en general LATHROP (2009), y TANAKA (2009).
} 
entre las partes, y que se refleja en el Convenio sobre Zona Especial Fronteriza Marítima de 1954, no se extiende más allá de las 80 millas náuticas del paralelo geográfico ${ }^{44}$.

Habiendo resuelto que hay una frontera marítima, la CIJ procedió a identificar su punto de inicio. Para esto, le asignó importancia al entendimiento existente en 1968 al momento de realizar las marcas de enfilación en torno al "Hito No 1", considerado por los delegados de las partes que comenzaron los preparativos para la instalación de faros a cada lado de la frontera terrestre entre Chile y Perú como indicativo del límite marítimo parale$10^{45}$. Al respecto, el tribunal agregó que no había sido llamado a determinar la posición del punto "Concordia", donde la frontera terrestre entre las partes empieza, e indicó que es posible que este punto no coincida con el inicio del límite marítimo ya definido, lo cual "sería una consecuencia de los acuerdos alcanzados entre las partes” ${ }^{36}$. Al no ser Perú parte de la Convemar e invocar sus disposiciones como costumbre internacional, la CIJ consideró que dicho Estado se ha comprometido formalmente a aplicar su llamado "dominio marítimo" sobre las 200 millas náuticas que esta área comprende de una manera consistente con dicho tratado ${ }^{47}$. De acuerdo al tribunal, el curso de la frontera marítima a partir del así denominado "punto A" (ubicado a 80 millas marinas contadas desde la intersección del paralelo de latitud sur que pasa por el "Hito No 1 " y la línea de baja marea) debe responder al principio de equidistancia de los artículos 74 y 83 de la Convemar, que reflejan el derecho internacional consuetudinario en la materia ${ }^{48}$.

Siguiendo al asunto de la delimitación maritima en el Mar Negro (Rumania c. Ucrania) y a la disputa territorial y marítima (Nicaragua c. Colombia), la CIJ empleó un método de solución equitativa dividido en las tres etapas siguientes: primero, el tribunal traza una línea equidistante provisional si las costas relevantes son adyacentes, o una línea media entre ambas si las costas son opuestas, a menos que hayan razones de peso que impidan el trazado de esta línea; en seguida, considera si hay circunstancias pertinentes que puedan motivar el ajuste de esa línea, a fin de alcanzar un resultado equitativo; y finalmente, lleva a cabo un examen de desproporcionalidad, a través del cual evalúa el efecto de la línea ajustada en los estados litigantes, de tal manera que sus áreas respectivas se conformen en general a la longitud de sus costas, evitando así una solución inequitativa ${ }^{49}$. En este caso, el tribunal

\footnotetext{
44 Ver disputa marítima, Perú c. Chile (2014): CIJ (sentencia) párrafos 149 \& 151. Ver también disputa maritima, Perú c. Chile (2014): CIJ (sentencia) párrafos 119-20, 122-3, 125-31, 133-8, 141-8 \& 150.

45 Ver disputa maritima, Perú c. Chile (2014): CIJ (sentencia) párrafos 164-74, 176-7 \& 198.

46 Disputa marítima, Perú c. Chile (2014): CIJ (sentencia) párrafo 175. Ver también disputa marítima, Perú c. Chile (2014): CIJ (sentencia) párrafo 163.

47 Ver disputa marítima, Perú c. Chile (2014): CIJ (sentencia) párrafo 178. Sobre Perú y la Convemar, ver LAgos Erazo (2010) pp. 170-1, y Lagos Erazo (2014b) pp. 53-5.

48 Ver disputa marítima, Perú c. Chile (2014): CIJ (sentencia) párrafos 179 \& 198. La CIJ citó los casos de Qatar con Bahréin, y de Nicaragua con Colombia. Ver asunto de la delimitación marítima y cuestiones territoriales, Qatar c. Bahréin (2001): CIJ (sentencia) párrafo 167; y disputa territorial y marítima, Nicaragua c. Colombia (2012): CIJ (sentencia) párrafo 139. En cuanto al asunto de la delimitación marítima y cuestiones territoriales entre Qatar y Bahréin, ver en general Jiuyong (2010), y Mendelson (2011).

49 Ver disputa maritima, Perú c. Chile (2014): CIJ (sentencia) párrafo 180. Ver también asunto de la delimitación maritima en el Mar Negro, Rumania c. Ucrania (2009): CIJ (sentencia) párrafos 101-3; y disputa territorial y maritima, Nicaragua c. Colombia (2012): CIJ (sentencia) párrafos 190-3. Respecto a los métodos de delimita-
} 
procedió a trazar una línea que va desde el "punto A" a un "punto B" (coincidente con el cruce de la línea equidistante y la zona económica exclusiva chilena), para luego bajar a un “punto C” (en la intersección de la nueva zona marítima de Perú con las 200 millas náuticas bajo soberanía y jurisdicción de Chile $)^{50}$. La CIJ finalmente señaló que son las partes litigantes quienes deben acordar las coordenadas precisas de este límite marítimo ${ }^{51}$.

\section{UN ANTECEDENTE JURISPRUDENCIAL}

El 19 de noviembre del 2012, la CIJ dictó su sentencia en la disputa territorial y marítima (Nicaragua c. Colombia). Hay más de una similitud entre este caso y el que enfrentó a Perú con Chile. Para apreciarlas bien, es necesario revisar brevemente en qué consistió esta controversia internacional. El 2001, Nicaragua presentó una solicitud contra Colombia donde reclamaba la soberanía de la totalidad del Archipiélago de San Andrés, Providencia y Santa Catalina, y le pedía a la CIJ que delimite la frontera marítima entre ambos Estados en el Caribe occidental, a través de una línea media a trazar entre las costas continentales de Nicaragua y Colombia ${ }^{52}$. A diferencia del camino que seguiría Chile unos años después, Colombia presentó excepciones preliminares a la jurisdicción del tribunal el 2002, suspendiendo así el procedimiento sobre el fondo del asunto ${ }^{53}$. En su decisión sobre dichas excepciones del 13 de diciembre del 2007, la CIJ concluyó que era competente para conocer el caso en virtud del artículo XXXI del Pacto de Bogotá, con exclusión de lo relacionado a la soberanía de las islas de San Andrés, Providencia y Santa Catalina ${ }^{54}$. Para el tribunal, estas islas son colombianas según lo dispuesto en el Tratado sobre Cuestiones Territoriales

ción marítima utilizados por la CIJ, ver TANAKA (2006) pp. 51-126; TANAKA (2008) pp. 913-24; TANAKA (2009) pp. 413-9; TANAKA (2012) pp. 186-216; y TANAKA (2013) pp. 914-9.

50 Ver disputa marítima, Perú c. Chile (2014): CIJ (sentencia) párrafos 183-6, 190-6 \& 198.

51 Ver disputa marítima, Perú c. Chile (2014): CIJ (sentencia) párrafo 197. En cuanto a la implementación de la sentencia por Chile y Perú, ver Lagos Erazo (2014b) pp. 234-42; y Llanos y Cabrera (2014) pp. 688-92.

52 Ver disputa territorial y marítima, Nicaragua c. Colombia (2012): CIJ (sentencia) párrafo 1. Ver también PRIeTO y LozAno (2013) pp. $22 \& 71-8$. Sobre el origen de la controversia entre Nicaragua y Colombia, ver disputa territorial y marítima, Nicaragua c. Colombia (2007): CIJ (excepciones preliminares) párrafos 15-32. Ver también Abello (2013) pp. 75-6; y Prieto y Lozano (2013) pp. 50-66 \& 69-71.

53 Ver disputa territorial y marítima, Nicaragua c. Colombia (2012): CIJ (sentencia) párrafo 5. Ver también Prieto y Lozano (2013) pp. 78-84.

${ }^{54}$ Ver disputa territorial y marítima, Nicaragua c. Colombia (2012): CIJ (sentencia) párrafo 6. Ver también disputa territorial y maritima, Nicaragua c. Colombia (2007): CIJ (excepciones preliminares) párrafos 38-42, 502, 54-9, 63-72, 77-82, 88-90, 96-7, 104, 115-20, 132-40 \& 142. En cuanto a la decisión de la CIJ sobre excepciones preliminares en la disputa territorial y marítima entre Nicaragua y Colombia, ver Abello (2013) pp. 53-7, 60, 63-4 \& 76-8; y Prieto y Lozano (2013) pp. 85-95. Ver en general Nieto (2009). Unos pocos meses antes de esta decisión, la CIJ falló la disputa territorial y marítima (Nicaragua c. Honduras). Sobre la relación entre este caso y el de Nicaragua con Colombia, ver Abello (2013) pp. 56 \& 62-3. En la disputa territorial y marítima (Nicaragua c. Colombia), la CIJ tuvo además que resolver las solicitudes de terceros Estados que buscaban participar en la controversia. El tribunal rechazó ambas solicitudes. Ver en general disputa territorial y marítima, Nicaragua c. Colombia (2012): CIJ (solicitud de Costa Rica para intervenir); y disputa territorial y maritima, Nicaragua c. Colombia (2012): CIJ (solicitud de Honduras para intervenir). Ver también Prieto y Lozano (2013) pp. 95-104 \& 132-3. En cuanto al efecto de esta sentencia en terceros estados, ver TANAKA (2013) pp. 927-9 \& 931. 
entre Colombia y Nicaragua de 1928, mejor conocido como Tratado Esguerra-Bárcenas por los apellidos de los presidentes que lo firmaron ${ }^{55}$.

La sentencia del 19 de noviembre del 2012 no solo confirmó que las islas de San Andrés, Providencia y Santa Catalina son colombianas, sino que reconoció la soberanía del Estado demandado sobre las otras formaciones que integran el archipiélago del mismo nombre, respecto de la cuales el Tratado Esguerra-Bárcenas no se había pronunciado: vale decir, los cayos Albuquerque, Bajo Nuevo, del Este-Sudeste, Quitasueño, Roncador, Serrana y Serranilla ${ }^{56}$. Sin embargo, y contra lo argumentado por Colombia, la CIJ resolvió que su frontera marítima con Nicaragua no estaba delimitada; por lo que procedió a establecer los contornos del área relevante sobre la cual recaería su fallo, señalando que las costas pertinentes de las partes en litigio eran las del continente - para Nicaragua- y las de las islas del Archipiélago de San Andrés, Providencia y Santa Catalina -para Colombia ${ }^{57}$-. Empleando el mismo método de solución equitativa que utilizó más tarde en el caso entre Perú y Chile, la CIJ estableció el curso del límite marítimo entre Colombia y Nicaragua, trazando un área de navegación semirrectangular en torno a las islas y cayos que se encuentran al suroeste del Archipiélago de San Andrés, Providencia y Santa Catalina, y dejando a los cayos ubicados al norte del mismo -i.e. Quitasueño y Serrana- enclavados junto a su mar territorial de 12 millas náuticas en una zona económica exclusiva que hoy corresponde a Nicaragua ${ }^{58}$. Como bien dijera Rafael Prieto, con su fallo la CIJ le entregó a Colombia la tierra y a Nicaragua el mar ${ }^{59}$.

Pero ¿en qué se parece este caso al de Perú con Chile? Al menos en los siguientes aspectos: rechazo del statu quo por el Estado demandante; inexistencia de ganancia para el estado demandando, cualquiera sea el resultado del juicio; desconocimiento de tratados limítrofes por el demandante; sorpresa en el demandado ante una controversia sobre territorios que había poseído por décadas; utilización del Pacto de Bogotá como base de jurisdicción del tribunal; invocación de las disposiciones de la Convemar como normas consuetudinarias, por no ser parte en ese tratado uno de los Estados litigantes; solución jurisprudencial creativa y polémica al problema de la delimitación marítima; molestia en el demandado ante el criterio empleado por la CIJ para determinar dicha frontera; caída en desgracia en ese estado del mecanismo de solución de controversias internacionales establecido en el Pacto

55 El Tratado sobre Cuestiones Territoriales entre Colombia y Nicaragua de 1928 está disponible en: <http:// www.sogeocol.edu.co/documentos/trat_col_nicaragua.pdf> [fecha de consulta: 30 de septiembre de 2014]. Respecto al Archipiélago de San Andrés, Providencia y Santa Catalina, ver Prieto y Lozano (2013) pp. 26-31.

56 Ver disputa territorial y maritima, Nicaragua c. Colombia (2012): CIJ (sentencia) párrafos 103 \& 251. Ver también disputa territorial y maritima, Nicaragua c. Colombia (2012): CIJ (sentencia) párrafos 26, 34-8, 52-5, 64-5, 67-8, 71, 80-1, 83-4, 88-90, 95, 100-3 \& 251. Sobre estas formaciones del Archipiélago de San Andrés, Providencia y Santa Catalina, ver Prieto y Lozano (2013) pp. 32-44; y TANAKa (2013) pp. 910-3.

57 Ver disputa territorial y maritima, Nicaragua c. Colombia (2012): CIJ (sentencia) párrafos 164-6 \& 251. Ver también disputa territorial y marítima, Nicaragua c. Colombia (2012): CIJ (sentencia) párrafos 136, 139-41, $145,150-4 \& 157-66$.

58 Ver disputa territorial y marítima, Nicaragua c. Colombia (2012): CIJ (sentencia) párrafos 180, 182-3, 22938 \& 251. Ver también disputa territorial y marítima, Nicaragua c. Colombia (2012): CIJ (sentencia) párrafos 175-9, 200-5, 209-111, 214-6, 219-20, 222-3, 226-8 \& 239-47. Respecto a la sentencia de la CIJ en la disputa territorial y marítima entre Nicaragua y Colombia, ver Cárdenas y Herrera (2013) pp. 244-6; Prieto y LozaNo (2013) pp. 105-28; ReICHLer (2013) pp. 130-2 \& 134-51; y TANAKA (2013) pp. 910-29.

59 Ver Prieto y Lozano (2013) n. 4 en p. 20 \& p. 143. 
de Bogotá; y surgimiento de nuevas controversias actuales o eventuales entre las partes del litigio, provocadas por la sentencia del tribunal internacional. Cabe presumir, asimismo, que la experiencia de Nicaragua como demandante y de Colombia como demandado fueron claves en la conducta judicial seguida más tarde por Perú y Chile. Por ejemplo, ¿̨fue una simple coincidencia que Perú haya presentado su solicitud a la CIJ alrededor de un mes después que esta resolviera tener jurisdicción para conocer del caso de Nicaragua con Colombia en virtud del Pacto de Bogotá? Y ¿qué otra razón tuvo Chile para no objetar la competencia del tribunal, sino evitar una decisión sobre excepciones preliminares que se anticipaba contraria, y que bien podría haber tenido un impacto político negativo en el ámbito interno?

Tanto en Colombia como después en Chile, las sentencias de la CIJ fueron criticadas. En la disputa del Mar Caribe se le reprochó al tribunal el raciocinio utilizado y las conclusiones a las que llegó en su fallo. Se dijo que este reflejaba más una decisión ex aequo et bono, que una sentencia dictada conforme a derecho ${ }^{60}$. Esta misma línea argumental contraria a la labor de la CIJ sería recogida poco después en Chile, respecto de la disputa del Océano Pacífico ${ }^{61}$. La disconformidad con el trabajo de la CIJ tuvo mucho que ver con el hecho que la delimitación fronteriza jurisprudencial le significó a Colombia perder unos $75.000 \mathrm{~km}^{2}$, y a Chile unos $22.000 \mathrm{~km}^{2}$ de territorio marítimo ${ }^{62}$. En ambos casos, el Estado demandado vio reducida principalmente su zona económica exclusiva, incluyendo aguas, suelo y subsuelo. Si la CIJ hubiera aceptado la interpretación de los tratados invocados por Colombia y Chile, tendría necesariamente que haber rechazado las peticiones de Nicaragua y Perú. Esto explica que el tribunal haya optado por una solución intermedia: que el Tratado Esguerra-Bárcenas establece la soberanía de Colombia sobre el Archipiélago de San Andrés, Providencia y Santa Catalina, pero no delimita la frontera marítima con Nicaragua, y que el acuerdo tácito producido entre la Declaración de Santiago de 1952 y el Convenio sobre Zona Especial Fronteriza Marítima de 1954 solo llega a las 80 millas náuticas desde el límite de Chile con Perú ${ }^{63}$. Lo anterior le permitió a la CIJ aplicar el método equitativo de delimitación marítima para las dos controversias internacionales, dividiendo el territorio marítimo disputado en desmedro del estado demandado, quien hasta ese momento ocupaba la totalidad de dichas aguas, suelo y subsuelo.

\section{PROBLEMAS Y PREGUNTAS}

Son muchas las críticas puntuales que se le han hecho a las sentencias de la CIJ en las controversias de Nicaragua con Colombia, y de Perú con Chile. En cuanto a la disputa

\footnotetext{
60 Ver e.g. Cárdenas y Herrera (2013) pp. 247-9. Ver también el art. 38.2 del Estatuto de la Corte Internacional de Justicia de 1945. Disponible en: <http://www.icj-cij.org/homepage/sp/icjstatute.php> [fecha de consulta: 30 de septiembre de 2014].

61 Ver e.g. Aguayo (2014) pp. 101-2, y Lagos Erazo (2014) pp. 171-3, 189 \& 196.

62 Ver Abello (2013) p. 49; Cárdenas y Herrera (2013) p. 246; Lagos Erazo (2013) pp. 173-4 \& 176; Prieto y Lozano (2013) p. 130; Llanos y Cabrera (2014) pp. 674 \& 679-80; y Rodríguez Elizondo (2014) pp. $211-2$.

63 Sobre la interpretación de los tratados invocados por Colombia y Chile en sus respetivas disputas con Nicaragua y Perú, ver Abello (2013) pp. 57-8, 63-4, 77, 80 \& 83-4; y Prieto y Lozano (2013) pp. 85-95; y AguAYO (2014) pp. 91-8 \& 101-2.
} 
del Mar Caribe se pueden mencionar, entre otras, la restricción de los efectos del Tratado Esguerra-Bárcenas de 1928 a las islas y cayos; la poca importancia dada por el tribunal a la práctica estatal en la configuración de los límites marítimos; el desplazamiento de la línea de dicha frontera; el trazado del área semirrectangular alrededor del Archipiélago de San Andrés, Providencia y Santa Catalina; y el consecuente aislamiento de los cayos Quitasueño y Roncador del resto del territorio marítimo colombiano ${ }^{64}$. Respecto a la disputa del Océano Pacífico, los principales cuestionamientos apuntaron a la valoración que le dio la CIJ a la Declaración de Santiago de 1952; la determinación de la existencia de un acuerdo tácito no alegado por las partes litigantes; la valoración dada a la práctica estatal, la partición del límite marítimo a contar de las 80 millas náuticas; y la subsistencia de la controversia respecto del triángulo terrestre ${ }^{65}$. Como en el diferendo de Nicaragua con Colombia, en la controversia de Perú con Chile las críticas no solo vinieron de la doctrina, sino también de algunos de los miembros de la $\mathrm{CIJ}^{66}$. De hecho, es en las opiniones disidentes y separadas y en las declaraciones de sus jueces, donde se puede realmente percibir la riqueza del debate que se produjo al interior del tribunal en este caso. Así, los jueces Dalveer Bhandari, Giorgio Gaja, Xue Hanquin y Francisco Orrego Vicuña cuestionaron en su opinión disidente conjunta que el tribunal no haya indicado cuándo y dónde se alcanzó el acuerdo tácito entre Chile y Perú ${ }^{67}$. Estos jueces además señalaron que la CIJ debería haber interpretado el párrafo IV de la Declaración sobre Zona Marítima de 1952 conforme al principio de la efectividad de los tratados ${ }^{68}$. De haberlo hecho, el tribunal habría concluido que cada una de las fronteras marítimas entre los Estados parte de la Declaración de Santiago quedaron delimitadas por los paralelos geográficos, y que se extenderían hasta las 200 millas marinas desde la respectiva costa ${ }^{69}$. Según Bhandari, Gaja, Xue y Orrego, esta circunstancia habría sido confirmada por el Convenio sobre Zona Especial Fronteriza Marítima de 1954, el Protocolo de Accesión de 1955 a la Declaración de Santiago, y las actas de instalación de los faros de 1968 y $1969^{70}$.

${ }^{64}$ Ver Abello (2013) pp. 82-93; Cárdenas y Herrera (2013) pp. 244-6; Prieto y Lozano (2013) pp. 105-28; y TANAKA (2013) pp. 910-29.

65 Ver Lagos Erazo (2013) pp. 159-75; Aguayo (2014) pp. 91-102; Badilla (2014) pp. 489-92 \& 494-5; Llanos y Cabrera (2014) pp. 671-80 \& 683-3; y Rodríguez Elizondo (2014) pp. 207-17.

En cuanto al acuerdo tácito, ver en general ABUGaTTAS (2014).

${ }^{66}$ Respecto del diferendo entre Colombia y Nicaragua, ver en general disputa territorial y marítima, Nicaragua c. Colombia (2012): CIJ (declaración del juez Keith); disputa territorial y maritima, Nicaragua c. Colombia (2012): CIJ (declaración del juez Xue); disputa territorial y marítima, Nicaragua c. Colombia (2012): CIJ (opinión individual del juez Abraham); y disputa territorial y marítima, Nicaragua c. Colombia (2012): CIJ (declaración del juez ad hoc Cot).

${ }^{67}$ Ver disputa marítima, Perú c. Chile (2014): CIJ (opinión separada de los jueces Bhandari, Gaja, Xue y Orrego) párrafo 1.

${ }_{68}$ Ver disputa marítima, Perú c. Chile (2014): CIJ (opinión separada de los jueces Bhandari, Gaja, Xue y Orrego) párrafos $2 \& 6$.

${ }^{69}$ Ver disputa marítima, Perú c. Chile (2014): CIJ (opinión separada de los jueces Bhandari, Gaja, Xue y Orrego) párrafos 2-17 \& 35 .

${ }^{70}$ Ver disputa marítima, Perú c. Chile (2014): CIJ (opinión separada de los jueces Bhandari, Gaja, Xue y Orrego) párrafos 18-35. 
El juez Bernardo Sepúlveda Amor expresó no estar de acuerdo con el razonamiento de la CIJ sobre el acuerdo tácito de Chile y Perú. En su declaración, señaló que nada relevante ocurrió entre 1952 y 1954 que justifique la existencia de dicho acuerdo ${ }^{71}$. Considerando que el estándar de prueba establecido el 2007 en la disputa territorial y maritima (Nicaragua c. Honduras) es estricto, mal podría la CIJ haber resuelto que el Convenio sobre Zona Especial Fronteriza Marítima de 1954 confirmó un acuerdo tácito entre las partes litigantes, sin haber realizado un análisis previo riguroso ${ }^{72}$. El juez Hisashi Owada concordó en gran medida con esto. En su opinión separada reiteró que el estándar de prueba para un acuerdo tácito es alto, según lo dispuesto en el caso de Nicaragua con Honduras ${ }^{73}$. A juicio de Owada, la CIJ no alcanzó dicho estándar en la disputa de Perú con Chile, lo que pondría en duda la extensión de 80 millas náuticas asignada al límite marítimo acordado tácitamente por los litigantes ${ }^{74}$. La jueza Julia Sebutinde fue más allá en este punto. En su opinión disidente, indicó que el tribunal no cumplió con el estándar probatorio del caso de Nicaragua con Honduras ${ }^{75}$. Al no haber un acuerdo tácito que establezca los límites marítimos entre las partes en litigio, Sebutinde concluyó que la CIJ debería haber procedido a delimitar de novo la frontera marítima entre Chile y Perú, a partir de la intersección del paralelo geográfico que pasa por el Hito $\mathrm{N}^{0} 1$ y la costa respectiva ${ }^{76}$. Por su parte, el juez Peter Tomka agregó una declaración a la sentencia del 2014 que él mismo describió como "una opinión en parte concurrente y en parte disidente" 77 . Tomka no estuvo de acuerdo con la partición del límite marítimo entre Chile y Perú que hizo el tribunal, por cuanto de los instrumentos jurídicos invocados por los litigantes se desprende que su delimitación fue efectuada conforme al paralelo geográfico y que se extiende hasta las 200 millas marinas $^{78}$. En su declaración, el juez Giorgio Gaja se manifestó contrario a la existencia de puntos distintos para el inicio de las fronteras terrestre y marítima entre Chile y Perú ${ }^{79}$. Por último, los jueces ad hoc Gilbert Guillaume y Francisco Orrego Vicuña anexaron a la sentencia de la CIJ una declaración y una opinión separada, respectivamente. Guillaume consideró que la intersección de la línea de baja marea y el paralelo sur que pasa por el Hito $N^{\circ} 1$ marca el inicio del límite marítimo, pero no el de la frontera terrestre, que estaría constituido por el punto Concordia. Esto dejaría el triángulo terrestre bajo la soberanía peruana, aun cuando su mar adyacente corresponda a Chile ${ }^{80}$. Orrego se mostró en desacuerdo con el quiebre del

\footnotetext{
${ }^{71}$ Ver disputa marítima, Perú c. Chile (2014): CIJ (declaración del juez Sepúlveda Amor) párrafos 8-9 \& 16.

72 Ver disputa marítima, Perú c. Chile (2014): CIJ (declaración del juez Sepúlveda Amor) párrafos 1-7 \& 10-8. Ver también disputa territorial y maritima, Nicaragua c. Honduras (2007): CIJ (sentencia) párrafo 253.

73 Ver disputa maritima, Perú c. Chile (2014): CIJ (opinión separada del juez Owada) párrafo 12. Ver también disputa territorial y maritima, Nicaragua c. Honduras (2007): CIJ (sentencia) párrafo 253.

74 Ver en general disputa maritima, Perú c. Chile (2014): CIJ (opinión separada del juez Owada).

75 Ver disputa maritima, Perú c. Chile (2014): CIJ (opinión disidente de la jueza Sebutinde) párrafos 6-7 \& 14-5. Ver también disputa territorial y marítima, Nicaragua c. Honduras (2007): CIJ (sentencia) párrafo 253.

76 Ver en general disputa marítima, Perú c. Chile (2014): CIJ (opinión disidente de la jueza Sebutinde).

77 Disputa marítima, Perú c. Chile (2014): CIJ (declaración del juez Tomka) párrafo 1.

${ }_{78}$ Ver en general disputa marítima, Perú c. Chile (2014): CIJ (declaración del juez Tomka).

79 Ver en general disputa maritima, Perú c. Chile (2014): CIJ (declaración del juez Gaja).

${ }^{80}$ Ver disputa marítima, Perú c. Chile (2014): CIJ (declaración del juez ad hoc Guillaume) párrafo 15.
} 
límite marítimo a partir de las 80 millas náuticas, debido a que los instrumentos jurídicos invocados por los litigantes no permiten llegar a esta conclusión ${ }^{81}$.

Tras la lectura de la sentencia que puso término a la disputa del Mar Caribe el 2012, la disconformidad con el trabajo de la CIJ llegó a tal punto en Colombia que pocos días después de conocido el fallo su Estado denunció el Tratado Americano de Soluciones Pacíficas, paradójicamente celebrado en Bogotá en 1948 ${ }^{82}$. Una vez leída la sentencia recaída en el diferendo del Océano Pacífico el 2014, en Chile se discutió seriamente esa posibilidad sin que llegara a materializarse ${ }^{83}$. Esto ya es de por sí una mala noticia para la solución de controversias internacionales en Latinoamérica. Si a eso le sumamos el surgimiento de nuevas disputas en el Mar Caribe, donde Nicaragua y Colombia figuran como litigantes ante la CIJ, y la tensión latente que dejó la innecesaria declaración del tribunal respecto del inicio de la frontera terrestre entre Chile y Perú, corresponde preguntarse si las últimas decisiones de la CIJ realmente están contribuyendo a la solución de conflictos internacionales, o más bien están alentando la revisión judicial de las fronteras interestatales en la región. En este contexto, Nicaragua presentó el 16 de septiembre del 2013 una solicitud ante la CIJ en contra de Colombia, donde pide la delimitación de la plataforma continental más allá de las 200 millas marinas de su costa ${ }^{84}$. Lo resuelto sobre dicho asunto en la disputa territorial y maritima (Nicaragua c. Colombia) hizo posible esta segunda solicitud ${ }^{85}$. El 26 de noviembre del 2013, Nicaragua presentó una tercera solicitud en contra de Colombia por supuestas violaciones de los derechos soberanos y las zonas marítimas adjudicadas a su favor en la sentencia del año anterior ${ }^{86}$.

En la disputa maritima (Perú c. Chile), el tribunal internacional optó expresamente por no resolver el problema del triángulo terrestre, cuyos vértices estarían conformados por el Hito $\mathrm{N}^{\circ} 1$, el lugar en el que la proyección del paralelo geográfico toca la costa y el así llamado punto Concordia ${ }^{87}$. La aceptación por la CIJ del inicio del límite marítimo entre Chile y Perú en la intersección del paralelo de latitud sur que atraviesa el Hito $\mathrm{N}^{\circ} 1$ con la línea de baja marea, bien se podría haber interpretado como un rechazo tácito del punto

81 Ver disputa marítima, Perú c. Chile (2014): CIJ (opinión separada del juez ad hoc Orrego) párrafos 12-28. El juez Orrego se manifestó, asimismo, contrario al otorgamiento del triángulo marítimo externo a Perú. Según él, de haberse aplicado el criterio del paralelo geográfico, Perú no habría tenido derecho a este reclamo. Ver disputa marítima, Perú c. Chile (2014): CIJ (opinión separada del juez ad hoc Orrego) párrafos 30-7.

82 Ver Prieto y Lozano (2013) pp. 106 \& 134-5, y Reichler (2013) p. 131. Ver en general Mateus (2013). Además de la denuncia del Pacto de Bogotá, Colombia retiró la declaración a través de la cual se sometía voluntariamente a la jurisdicción de la CIJ un día antes que Nicaragua presentara su solicitud ante el tribunal. Ver Abello (2013) pp. 52, 54, 56, 58, 61, 64 \& 77; y Prieto y Lozano (2013) pp. 82, 86-7 \& 89-90.

83 Ver Lagos Erazo (2013) pp. 219-24. Ver también Llanos y Cabrera (2014) pp. 683-5.

${ }^{84} \mathrm{La}$ información relativa al asunto de la plataforma continental más allá de las 200 millas marinas de la costa nicaragüense (Nicaragua c. Colombia) está disponible en: <http://www.icj-cij.org/docket/index.php?p1=3\&p2=3 $\&$ code $=$ nicolb \&case $=154 \& \mathrm{k}=02>$ [fecha de consulta: 30 de septiembre de 2014].

85 Ver disputa territorial y marítima, Nicaragua c. Colombia (2012): CIJ (sentencia) párrafos 104-31. Ver también Abello (2013) pp. 87-8; Prieto y Lozano (2013) pp. 23-4, 75-8, 110-1\& 134-41.

86 Todo lo relativo al asunto de las presuntas violaciones de los derecho soberanos y zonas marítimas de Nicaragua declaradas por la sentencia de la CIJ del 19 de noviembre de 2012 está disponible en: <http://www.icj-cij.org/docket/index.php?p1=3\&p2=3\&code=nicolc\&case=155\&k=37> [fecha de consulta: 30 de septiembre de 2014].

87 Ver Lagos Erazo (2013) pp. 198-209. Ver también Llanos y Cabrera (2014) pp. 685-8. 
Concordia reclamado por el Estado demandante ${ }^{88}$. Sin embargo, a fin de confirmar que su jurisdicción solo se extiende a la delimitación de la frontera marítima, el tribunal agregó un párrafo donde señaló que el Hito $\mathrm{N}^{\circ} 1$ puede no coincidir con el comienzo de la frontera terrestre, lo que sería una consecuencia de los acuerdos alcanzados por Chile y Perú ${ }^{89}$. Este acuerdo no sería otro que el Tratado de Lima de 1929. Al existir interpretaciones contrapuestas sobre el asunto, Chile y Perú debieran consentir en un nuevo acuerdo que resuelva esto. De lo contrario, el problema se podría solucionar a través del arbitraje del Presidente de EE.UU., conforme a lo estipulado en el artículo 12 del Tratado de Lima de $1929^{90}$. Considerando que dicho triángulo mediría aproximadamente 3,7 ha y su costa no tendría un mar asociado, estaríamos en presencia de un arbitraje ridículo. Así y todo, es un conflicto posible.

\section{CONCLUSIÓN}

La sentencia que resolvió la controversia entre Nicaragua y Colombia modificó el límite marítimo vigente de facto o de iure, según se esté de acuerdo con los argumentos de la parte demandante o de la demandada. En virtud de este fallo, las islas y cayos del Archipiélago de San Andrés, Providencia y Santa Catalina permanecieron bajo soberanía colombiana, y los cayos Quitasueño y Roncador quedaron insertos en una nueva zona económica exclusiva nicaragüense, aislados del área semirrectangular de territorio marítimo que rodea el mencionado archipiélago. Esta sentencia de la CIJ, y el rechazo que produjo en Colombia, fueron unánimes ${ }^{91}$. Conocido el fallo recaído en la disputa del Mar Caribe, el pesimismo cundió en Chile. Anticipando que algo se perdía en la controversia con Perú, sin saber exactamente qué, la sentencia dictada en el diferendo del Océano Pacífico fue recibida con resignación y no poco alivio en Chile ${ }^{92}$. Claro que esta vez, el fallo del tribunal internacional no fue unánime ${ }^{93}$. Esto demostraría que el acuerdo logrado entre los jueces en la sentencia del conflicto Nicaragua-Colombia, fue más difícil de alcanzar en el fallo de la controversia Perú-Chile. En este caso, la CIJ partió en dos el límite marítimo existente, delimitando la primera mitad conforme al paralelo geográfico y la segunda de acuerdo al método equitativo. Casualmente, la longitud de cada una de las partes de este nuevo límite entre Chile y Perú se acerca a las 100 millas marinas -el punto medio de la extensión total de la zona económica exclusiva, hasta ese momento bajo la soberanía y jurisdicción de facto o de iure chilenas. Lamentablemente, tanto esta sentencia del 2014 como la anterior

\footnotetext{
88 Ver disputa marítima, Perú c. Chile (2014): CIJ (sentencia) párrafos 164-74, 176-7 \& 198.

89 Ver disputa maritima, Perú c. Chile (2014): CIJ (sentencia) párrafo 175.

${ }^{\mathrm{Ver}}$ también disputa marítima, Perú c. Chile (2014): CIJ (sentencia) párrafo 163.

90 Esta disposición señala: Para el caso en que los Gobiernos de Chile y del Perú, no estuvieren de acuerdo en la interpretación que dén [sic] a cada una de las diferentes disposiciones de este Tratado y en que, a pesar de su buena voluntad, no pudieren ponerse de acuerdo, decidirá el Presidente de los Estados Unidos de América, la controversia.

91 Ver disputa territorial y maritima, Nicaragua c. Colombia (2012): CIJ (sentencia) párrafo 251.

Ver también Prieto y Lozano (2013) pp. 19-20, y ReIChler (2013) p. 131.

92 Ver Lagos Erazo (2013) pp. 182-91 \& 195-8.

93 Ver disputa maritima, Perú c. Chile (2014): CIJ (sentencia) párrafo 198.
} 
del 2012 confirman un recelo cada vez más extendido en América Latina hacia el trabajo de la CIJ. Si en la controversia de Nicaragua con Colombia a uno de los Estados se le dio el mar y al otro la tierra, en la disputa de Perú con Chile el mar se delimitó conforme a los dos métodos esgrimidos por los litigantes, en partes casi iguales. En otras palabras, ninguno de los Estados demandantes ganó todo lo reclamado, y ninguno de los demandados perdió todo lo defendido.

En este escenario, es difícil contrarrestar una apreciación que puede resultar muy perjudicial para la CIJ: que en la búsqueda de una solución pacífica para las controversias que le son sometidas, el tribunal no privilegia las consideraciones propiamente jurídicas que subyacen al caso respectivo, sobre otras de distinta naturaleza. Esto no equivale a sostener que la CIJ falla en equidad aquellas controversias que los Estados involucrados no han consentido expresamente que solucione ex aequo et bono. Todas las decisiones de la CIJ dictadas en ejercicio de su competencia contenciosa, se han basado en el derecho internacional aplicable al conflicto respectivo. El problema radica en otro lado. Está en la interpretación que ha dado el tribunal a las normas convencionales o consuetudinarias, o a los principios generales del derecho, invocados por las partes litigantes. La dificultad que esto plantea no es menor. Por un lado, las sentencias recientes del tribunal dan una señal equívoca a los Estados que no están conformes con un determinado statu quo, quienes pueden concluir que su revisión judicial es una alternativa que ofrece altas probabilidades de cambio. Por otro, la modificación de la realidad fronteriza que producen estas sentencias puede provocar diferendos con los otros Estados limítrofes de las partes litigantes, además de crear nuevos conflictos entre los mismos Estados en litigio. La competencia judicial debe ser siempre ejercida con cuidado. Más aún, si es la de un tribunal internacional que adjudica disputas de límites territoriales, en ejercicio de una jurisdicción de base voluntaria.

\section{BIBLIOGRAFÍA}

AbELLo, Ricardo (2013): "Diferendo territorial y marítimo entre Nicaragua y Colombia: once años de pleito", en Trujlllo, Carlos, y Torres, María Lucía (edits.), Contribución de la Universidad del Rosario al debate sobre el fallo de La Haya: análisis del caso Nicaragua vs. Colombia (2013) pp. 49-95.

AbugatTas, Gattas (2014): "Análisis sobre la referencia a los acuerdos tácitos en algunos casos sobre delimitación marítima, con especial atención al asunto de la delimitación marítima entre Perú y Chile”, Agenda Internacional, vol. 21 No 32: pp. 79-105.

Aguayo, Francisca (2014): "Reflexiones sobre el derecho internacional y la delimitación marítima. Comentario del fallo de la Corte Internacional de Justicia en el caso de Perú c. Chile", Tribuna Internacional, vol. 3 N 5: pp. 87-102.

AgüEro, Marisol (2001): Consideraciones para la delimitación maritima del Perú (Lima,, Fondo Editorial del Congreso del Perú).

Badilla, Elvira (2014): “'Controversia marítima Perú contra Chile’. Comentario a la sentencia de la Corte Internacional de Justicia de fecha 27 de enero de 2014”, Revista de Derecho (de la Universidad Católica del Norte), vol. 21 No 1: pp. 483-96. 
BÁKula, Juan Miguel (1985): El dominio maritimo del Perú (Lima, Fundación M.J. Bustamante de la Fuente).

BÁKUlA, Juan Miguel (2008): La imaginación creadora y el nuevo régimen jurídico del mar. Perú y Chile: ¡el desacuerdo es posible? (Lima, Universidad del Pacífico).

BÁkula, Juan Miguel (2002): Perú entre la realidad y la utopía. 180 años de política exterior (Lima, Fondo de Cultura Económica).

Benadava, Santiago (1993): Historia de las fronteras de Chile (Santiago, Chile, Editorial Universitaria).

Cárdenas, Fabián, y Herrera, Viviana (2013): "Una dosis de subjetividad para nada sorpresiva o innovadora: la equidad y el caso Nicaragua vs. Colombia ante la CIJ", International Law: Revista colombiana de derecho internacional vol. 22: pp. 243-51.

Cluny, Claude Michel (2000): Atacama: essai sur la Guerre du Pacifique 1879-1883 (París, Francia, Éditions de la Différence).

DurÁn, Phillip (2014): La hora de los halcones: la trastienda del conflicto Chile-Perú en La Haya (Santiago, Chile, Editorial Planeta).

Farcau, Bruce (2000): Chile, Peru, and Bolivia in the War of the Pacific, 1879-1884 (Westport, EE. UU., Praeger Publishers).

FAURA, Guillermo (1977): El mar peruano y sus límites (Lima, Imprenta Amauta) 338 pp.

Ferrero, Eduardo (1979): El nuevo derecho del mar: el Perú y las 200 millas (Lima, Universidad del Pacífico).

FIgUeroA, Uldaricio (2007): La demanda maritima boliviana en los foros internacionales (Santiago, RIL Editores).

Jiuyong, S (2010): "Maritime Delimitation in the Jurisprudence of the International Court of Justice”, Chinese Journal of International Law, vol. $9 \mathrm{~N}^{\circ}$ 2: pp. 271-91.

Lagos Erazo, Jaime (2014): “Antecedentes procesales sobre la controversia marítima Perú c. Chile", Tribuna Internacional, vol. $3 \mathrm{~N}^{\circ}$ especial: pp. 33-59.

Lagos Erazo, Jaime (2014): Fallo de La Haya: controversia maritima Perú contra Chile (Santiago, J.C. Sáez Editor).

Lagos Erazo, Jaime (2010): Los límites maritimos con el Perú (Santiago, Editorial Andrés Bello).

Lathrop, Coalter (2009): "Maritime Delimitation in the Black Sea (Romania v. Ukraine). International Court of Justice, February 3, 2009”, American Journal of International Law, vol. $103 \mathrm{~N}^{\circ}$ 3: pp. 543-9.

LirA, Diego (2009): Aspectos jurídicos de las aspiraciones maritimas bolivianas (Santiago, Editorial Puerto de Palos).

Llanos Mansilla, Hugo, y Cabrera Orellana, Cristián (2014): El juicio internacional entre Chile y Perú. El proceso ante la Corte Internacional de Justicia: alegatos y fallo (Santiago, LegalPublishing) 693 pp.

Mateus, Andrea (2013): "Denuncia del Pacto de Bogotá: implicaciones jurídicas para Colombia”, en Trujillo, Carlos, y Torres, María Lucía (edits.), Contribución de la Universidad del Rosario al debate sobre el fallo de La Haya: análisis del caso Nicaragua vs. Colombia (2013) pp. 1-22.

Mendelson, Maurice (2011): “The Curious Case of Qatar v. Bahrain in the International Court of Justice”, British Yearbook of International Law, vol. 72: pp. 183-211. 
Nieto, Rafael (2009): "La decisión de la Corte Internacional de Justicia sobre excepciones preliminares en el caso Nicaragua v. Colombia", Anuario Colombiano de Derecho Internacional, vol. 2: pp. 11-57.

Pinochet de la Barra, Oscar (2004): Chile y Bolivia: ¡hasta cuándo! (Santiago, Lom Ediciones) $125 \mathrm{pp}$.

PRieto, Rafael, y LozAno, Andrea (2013): El fallo de La Haya en la controversia territorial y marítima (Nicaragua c. Colombia) (Bogotá, Editorial Ibáñez) 161 pp.

Reichler, Paul (2013): "A Case of Equitable Maritime Delimitation: Nicaragua and Colombia in the Western Caribbean Sea”, Tribuna Internacional, vol. 2 № 3: pp. 129-60.

Rodríguez Cuadros, Manuel (2007): Delimitación maritima con equidad. El caso de Perú y Chile (Lima, Ediciones Peisa) 416 pp.

Rodríguez Cuadros, Manuel (2010): La soberanía maritima del Perú: la controversia el Perú y Chile (Lima, Industrial Gráfica San Remo) 396 pp.

Rodríguez Elizondo, José (2009): De Charaña a La Haya: Chile, entre la aspiración marítima de Bolivia y la demanda marítima de Perú (Santiago, La Tercera Ediciones) 389 pp.

Rodríguez Elizondo, José (2012): "Demanda marítima peruana; el derecho como eufemismo", en Picand, Eduardo y Llanos Mardones, Hugo (edits.), Estudios de derecho internacional: libro homenaje al profesor Hugo Llanos Mansilla (Santiago, LegalPublishing) pp. 711-31.

Rodríguez Elizondo, José (2014): Historia de dos demandas: Perú y Bolivia contra Chile (Santiago, El Mercurio-Aguilar).

Rodríguez Elizondo, José (2010): "La demanda marítima peruana en su origen. Un caso de realismo mágico”, en LeIva Lavalle, Patricio (edit.), Diálogos sobre La Haya. El límite maritimo entre Chile y Perú (Santiago, Fundación Konrad Adenauer y Universidad Miguel de Cervantes) pp. 25-36.

Rodríguez Elizondo, José (2010): Temas para después de La Haya: Augusto Pinochet, la Concertación y Sebastián Piñera ante la estrategia peruana (Santiago, Editorial Planeta).

SAter, William (2007): Andean Tragedy. Fighting the War of the Pacific, 1879-1884 (Lincoln, EE. UU., University of Nebraska Press).

Tanaka, Yoshifumi (2006): Predictability and Flexibility in the Law of Maritime Delimitation (Portland, EE.UU., Hart Publishing).

TANaKa, Yoshifumi (2008): "Reflections on Maritime Delimitation in the Nicaragua/Honduras Case", Heidelberg Journal of International Law Vol. 68: pp. 903-37.

Tanaka, Yoshifumi (2009): "Reflections on Maritime Delimitation in the Romania/Ukraine Case before the International Court of Justice", Netherlands International Law Review, vol. $56 \mathrm{~N}^{\circ}$ 3: pp. 397-427.

TANAKA, Yoshifumi (2013): "Reflections on the Territorial and Maritime Dispute between Nicaragua and Colombia before the International Court of Justice", Leiden Journal of International Law, vol. $26 \mathrm{~N}^{\circ}$ 4: pp. 909-31.

TANaKa, Yoshifumi (2012): The International Law of the Sea (Cambridge, Cambridge University Press).

TAPIA VAldés, Jorge, y MARdones, Luciano (2011): La mediterraneidad de Bolivia y el factor peruano (Santiago, Editorial Jurídica de Chile).

Winter, Luis (2013): La defensa de Chile en La Haya (Santiago, Ediciones LYD). 


\section{NORMAS CITADAS}

Tratado de Paz y Amistad entre Chile y Perú de 1883.

Tratado de Paz, Amistad y Comercio entre Bolivia y Chile de 1904.

Tratado sobre Cuestiones Territoriales entre Colombia y Nicaragua de 1928.

Tratado de Paz y Amistad entre Chile y Perú de 1929.

Protocolo Complementario al Tratado de Paz y Amistad entre Chile y Perú de 1929.

Carta de la Naciones Unidas de 1945.

Estatuto de la Corte Internacional de Justicia de 1945.

Tratado Americano de Soluciones Pacíficas de 1948.

Declaración sobre Zona Marítima de 1952, formulada por Chile, Ecuador y Perú.

Convenio sobre Zona Especial Fronteriza Marítima de 1954, celebrado por Chile, Ecuador y Perú.

Convención de las Naciones Unidas sobre el Derecho del Mar de 1982.

\section{JURISPRUDENCIA CITADA}

Asunto de la delimitación maritima y cuestiones territoriales, Qatar c. Bahréin (2001): Corte Internacional de Justicia, 16 de marzo de 2001 (sentencia). Disponible en francés e inglés en: <http://www.icj-cij.org/docket/files/87/7027.pdf> [fecha de consulta: 16 de julio de 2014].

Disputa territorial y maritima, Nicaragua c. Honduras (2007): Corte Internacional de Justicia, 8 de octubre de 2007 (sentencia). Disponible en francés e inglés en: <http://www. icj-cij.org/docket/files/120/14075.pdf> [fecha de consulta: 16 de julio de 2014].

Disputa territorial y marítima, Nicaragua c. Colombia (2007): Corte Internacional de Justicia, 13 de diciembre de 2007 (excepciones preliminares). Disponible en francés e inglés en: <http://www.icj-cij.org/docket/files/124/14305.pdf> [fecha de consulta: 16 de julio de 2014].

Asunto de la delimitación maritima en el Mar Negro, Rumania c. Ucrania (2009): Corte Internacional de Justicia, 3 de febrero de 2009 (sentencia). Disponible en francés e inglés en: <http://www.icj-cij.org/docket/files/132/14987.pdf> [fecha de consulta: 16 de julio de 2014].

Disputa territorial y maritima, Nicaragua c. Colombia (2011): Corte Internacional de Justicia, 4 de mayo de 2011 (solicitud de Costa Rica para intervenir). Disponible en francés e inglés en: <http://www.icj-cij.org/docket/files/124/16482.pdf> [fecha de consulta: 16 de julio de 2014].

Disputa territorial y maritima, Nicaragua c. Colombia (2011): Corte Internacional de Justicia, 4 de mayo de 2011 (solicitud de Honduras para intervenir). Disponible en francés e inglés en: <http://www.icj-cij.org/docket/files/124/16500.pdf> [fecha de consulta: 16 de julio de 2014].

Disputa territorial y marítima, Nicaragua c. Colombia (2012): Corte Internacional de Justicia, 19 de noviembre de 2012 (sentencia). Disponible en francés e inglés en: <http:// www.icj-cij.org/docket/files/124/17164.pdf> [fecha de consulta: 16 de julio de 2014]. 
Disputa territorial y maritima, Nicaragua c. Colombia (2012): Corte Internacional de Justicia, 19 de noviembre de 2012 (declaración del juez Kenneth Keith). Disponible en francés e inglés en: <http://www.icj-cij.org/docket/files/124/17170.pdf> [fecha de consulta: 16 de julio de 2014].

Disputa territorial y maritima, Nicaragua c. Colombia (2012): Corte Internacional de Justicia, 19 de noviembre de 2012 (declaración del juez Xue Hanquin). Disponible en francés e inglés en: <http://www.icj-cij.org/docket/files/124/17172.pdf> [fecha de consulta: 16 de julio de 2014].

Disputa territorial y maritima, Nicaragua c. Colombia (2012): CIJ (declaración del juez ad hoc Jean Pierre Cot). Disponible en francés e inglés en: <http://www.icj-cij.org/docket/ files/124/17178.pdf> [fecha de consulta: 16 de julio de 2014].

Disputa territorial y maritima, Nicaragua c. Colombia (2012): Corte Internacional de Justicia, 19 de noviembre de 2012 (opinión individual del juez Ronny Abraham). Disponible en francés e inglés en: <http://www.icj-cij.org/docket/files/124/17168.pdf> [fecha de consulta: 16 de julio de 2014].

Disputa maritima, Perú c. Chile (2014): Corte Internacional de Justicia, 27 de enero de 2014 (sentencia). Disponible en inglés en: <http://www.icj-cij.org/docket/files/137/17930.pdf> [fecha de consulta: 16 de julio de 2014].

Disputa maritima, Perú c. Chile (2014): Corte Internacional de Justicia, 27 de enero de 2014 (declaración del juez Giorgio Gaja). Disponible en inglés en: <http://www.icj-cij. org/docket/files/137/17950.pdf> [fecha de consulta: 16 de julio de 2014].

Disputa maritima, Perú c. Chile (2014): Corte Internacional de Justicia, 27 de enero de 2014 (declaración del juez Bernardo Sepúlveda Amor). Disponible en inglés en: <http://www. icj-cij.org/docket/files/137/17940.pdf> [fecha de consulta: 16 de julio de 2014].

Disputa maritima, Perú c. Chile (2014): Corte Internacional de Justicia, 27 de enero de 2014 (declaración del juez Peter Tomka). Disponible en inglés en: <http://www.icj-cij. org/docket/files/137/17938.pdf> [fecha de consulta: 16 de julio de 2014].

Disputa maritima, Perú c. Chile (2014): Corte Internacional de Justicia, 27 de enero de 2014 (declaración del juez ad hoc Gilbert Guillaume). Disponible en inglés en: <http:// www.icj-cij.org/docket/files/137/17954.pdf> [fecha de consulta: 16 de julio de 2014].

Disputa maritima, Perú c. Chile (2014): Corte Internacional de Justicia, 27 de enero de 2014 (opinión disidente de la jueza Julia Sebutinde). Disponible en inglés en: <http:// www.icj-cij.org/docket/files/137/17952.pdf> [fecha de consulta: 16 de julio de 2014].

Disputa marítima Perú c. Chile (2014): Corte Internacional de Justicia, 27 de enero de 2014 (opinión disidente conjunta de los jueces Dalveer Bhandari, Giorgio Gaja, Xue Hanquin y Francisco Orrego Vicuña). Disponible en inglés en: <http://www.icj-cij.org/ docket/files/137/17946.pdf> [fecha de consulta: 16 de julio de 2014].

Disputa maritima, Perú c. Chile (2014): Corte Internacional de Justicia, 27 de enero de 2014 (opinión separada del juez Hisashi Owada). Disponible en inglés en: <http:// www.icj-cij.org/docket/files/137/17942.pdf> [fecha de consulta: 16 de julio de 2014].

Disputa maritima, Perú c. Chile (2014): Corte Internacional de Justicia, 27 de enero de 2014 (opinión separada del juez ad hoc Francisco Orrego Vicuña). Disponible en inglés en: <http:// www.icj-cij.org/docket/files/137/17956.pdf> [fecha de consulta: 16 de julio de 2014]. 
